\title{
Fosaprepitant dimeglumine for the management of chemotherapy-induced nausea and vomiting: patient selection and perspectives
}

This article was published in the following Dove Press journal:

Cancer Management and Research

22 June 2016

Number of times this article has been viewed

\section{Nellowe Candelario \\ Marvin Louis Roy Lu}

Department of Medicine, Einstein Medical Center, Philadelphia, PA, USA
Correspondence: Nellowe Candelario Department of Medicine, Einstein Medical Center, 550I Old York Road, Philadelphia, PA 1914I, USA

Tel +I 2678585508

Email candelan@einstein.edu

\begin{abstract}
Chemotherapy-induced nausea and vomiting (CINV) is a debilitating side effect of antineoplastic agents. Several treatment regimens are used to address this problem. Fosaprepitant is a neurokinin-1 receptor blocker used in the prevention and treatment of CINV, especially for moderately and severely emetogenic chemotherapy. It is highly effective in the treatment of delayed CINV. Data from previous studies show that fosaprepitant is noninferior to aprepitant in the management of CINV. Fosaprepitant is given as a single-dose intravenous infusion, thus offering better patient compliance. The dose-limiting side effect of fosaprepitant is an infusionrelated reaction, ranging from pain at the infusion site to thrombophlebitis. This side effect has been reported with coadministration of anthracycline agents.
\end{abstract}

Keywords: chemotherapy nausea and vomiting, fosaprepitant, neurokinin inhibitor

\section{Introduction}

Cancer is the second leading cause of mortality in the United States after heart disease. ${ }^{1}$ Over the years, cancer survival has significantly improved due to a better understanding of cancer biology and the availability of various forms of treatment. One of the core modalities in cancer treatment is chemotherapy. A dreaded side effect, however, is chemotherapy-induced nausea and vomiting (CINV). Treatment for CINV has evolved over the past 2 decades and includes supportive and pharmacologic treatment. Controlling CINV improves the patient's functional status, quality of life, and capacity to perform activities of daily living. ${ }^{2,3}$ Nonpharmacologic management of CINV that has been described includes yoga, music therapy, acupressure, Concord grape, and ginger. A systematic review of these interventions has been done and showed insufficient evidence that the said interventions benefit patients with CINV. Non-pharmacologic interventions could be an adjunct given the low risk for toxicities. ${ }^{4}$ An important aspect in the management of CINV is patient education regarding the timing, prevention, and treatment of CINV. ${ }^{5}$ Several medications address the problem of acute and delayed CINV. The medications that are recommended vary with the emetogenic risk of a chemotherapeutic regimen. For highly emetogenic chemotherapy, a combination of a serotonin antagonist 5-hydroxytriptamine 3 (5-HT3), dexamethasone, and neurokinin inhibitor has been recommended. Palonosetron combined with dexamethasone is preferentially used for moderately emetogenic regimens. For low-risk patients, prechemotherapy dexamethasone is offered. ${ }^{3,6}$ The introduction of neurokinin inhibitors has greatly improved the ability to prevent and treat persistent CINV in patients 
receiving moderate to highly emetogenic chemotherapy. This review will focus on the use of the neurokinin inhibitor, fosaprepitant, in the management of CINV.

\section{Pathophysiology of CINV}

CINV is brought about by a complex process involving interconnected neurological pathways, neurotransmitters, and receptors. ${ }^{7}$ Emetogenic receptors are concentrated in three locations in the brainstem: the vomiting center in the medulla oblongata, the chemoreceptor trigger zone in the area postrema in the floor of the fourth ventricle, and the nucleus of the solitary tract. These areas are rich in 5-HT3, neurokinin-1 (NK-1), and dopamine (D) receptors. Serotonin, substance P, and dopamine bind to these receptors, respectively, to initiate the sensation of nausea and the vomiting reflex. ${ }^{8}$

The gastrointestinal tract is composed of mechanical and chemical receptors. Alterations in the chemical balance of different substances detected by chemoreceptors lead to the activation of vagal afferents, which leads to a cascade of events that then lead to nausea and vomiting. ${ }^{9,10}$ Most emetogenic antineoplastic drugs are toxic to the enterochromaffin cells lining the gastrointestinal tract that store and release serotonin. Exposure to these agents leads to the release of serotonin that binds to 5-HT3 receptors in the gut, thereby activating the vagal afferents in the gut and brainstem. ${ }^{11,12}$

The NK-1 receptor is the main receptor for the tachykinin family of peptides that includes substance P. Substance $\mathrm{P}$ has also been implicated in the pathogenesis of CINV. ${ }^{13}$ Substance $\mathrm{P}$ and NK-1 receptor are found in relevant sites (vagal afferent, nucleus tractus solitarius, and gastrointestinal mucosa) that are essential in the process of emesis. Binding of substance $P$ to NK-1 receptors initiates a cascade of events causing nausea and vomiting. Various stimuli that activate this pathway include chemotherapeutic agents such as cisplatin, radiation, opioids, apomorphine, and electrical stimulation of abdominal vagal afferents. The anatomical localization of these sites has led to the development of antagonists against NK-1 receptor in the treatment of CINV. ${ }^{14,9}$

\section{CINV}

CINV is a very common side effect of various antineoplastic agents. This greatly affects the quality of life of cancer patients. ${ }^{15}$ Risk factors identified for the development of CINV include female sex, alcohol use, and younger age. ${ }^{16-18}$ These risk factors also predict the failure of antiemetics for both prophylaxis and treatment of CINV (Table 1).

The risk of CINV also depends on the type of chemotherapy. The emetogenic potential is defined depending on
Table I Risk factors for CINV

\begin{tabular}{ll}
\hline Risk factors & Change in risk \\
\hline Sex & Greater risk in females \\
Age & Lower incidence at $<6$ or $>50$ years \\
Alcohol consumption & Lower incidence in individuals consuming \\
& $>10$ alcohol units/week \\
Motion sickness & Prior history leads to greater risk \\
Pregnancy-induced emesis & Prior history leads to greater risk \\
Anxiety & High anxiety levels correlated with greater \\
& risk \\
Previous cycles of & Poorly controlled nausea and vomiting in \\
chemotherapy & previous cycles increases the likelihood of \\
& CINV and anticipatory nausea and vomiting
\end{tabular}

Notes: Republished with permission of AlphaMed Press, from Schnell FM. Chemotherapy-induced nausea and vomiting: the importance of acute antiemetic control. Oncologist. 2003;8(2): 187-198; Copyright @ 2003 AlphaMed Press; permission conveyed through Copyright Clearance Center, Inc. ${ }^{15}$

Abbreviations: CINV, chemotherapy-induced nausea and vomiting.

Table 2 Emetogenic levels of antineoplastic drugs

\begin{tabular}{|c|c|c|c|}
\hline Minimal risk & Low risk & Moderate risk & High risk \\
\hline Bevacizumab & Bortezomib & Carboplatin & Carmustine \\
\hline Bleomycin & Cetuximab & $\begin{array}{l}\text { Cyclophosphamide } \\
\left(\leq 1.5 \mathrm{~g} / \mathrm{m}^{2}\right)\end{array}$ & Cisplatin \\
\hline Busulfan & $\begin{array}{l}\text { Cytarabine } \\
\left(\leq 100 \mathrm{mg} / \mathrm{m}^{2}\right)\end{array}$ & $\begin{array}{l}\text { Cytarabine } \\
\left(>1 \mathrm{~g} / \mathrm{m}^{2}\right)\end{array}$ & $\begin{array}{l}\text { Cyclophosphamide } \\
\left(>1.5 \mathrm{~g} / \mathrm{m}^{2}\right)\end{array}$ \\
\hline Cladribine & Docetaxel & Daunorubicin & Dacarbazine \\
\hline Fludarabine & Etoposide & Epirubicin & Mechlorethamine \\
\hline Vinblastine & Fluorouracil & Idarubicin & Streptozocin \\
\hline Vincristine & Gemcitabine & Ifosfamide & \\
\hline \multirow[t]{10}{*}{ Vinorelbine } & Ixabepilone & Irinotecan & \\
\hline & Lapatinib & Oxaliplatin & \\
\hline & Methotrexate & & \\
\hline & Mitomycin & & \\
\hline & Mitoxantrone & & \\
\hline & Paclitaxel & & \\
\hline & Pemetrexed & & \\
\hline & Temsirolimus & & \\
\hline & Topotecan & & \\
\hline & Trastuzumab & & \\
\hline
\end{tabular}

Notes: From N Engl J Med; Hesketh PJ; Chemotherapy-induced nausea and vomiting; 358(23);2482-2494; Copyright @ 2008 Massachusetts Medical Society. Reprinted with permission from Massachusetts Medical Society. ${ }^{18}$

the level of risk: minimal risk ( $<10 \%)$, low risk $(10 \%-30 \%)$, moderate risk (30\%-90\%), and high risk ( $>90 \%$ ) (Table 2$)$. CINV is classified based on the timing of occurrence: it may be acute if it occurs within initiation of chemotherapy (lasts $<24$ hours), delayed if it occurs after 24 hours (persisting for 6-7 days), or anticipatory (prior to chemotherapy administration). ${ }^{19}$

\section{Fosaprepitant}

Fosaprepitant (Emend for injection - Merck \& Co., Inc., Kenilworth, NJ, USA; Ivemend - Merck Sharp \& Dohme Ltd, Hertfordshire, Europe) is an NK-1 receptor antagonist that is approved for the treatment of CINV. It is an $N$-phosphoryl 
Table 3 Drug interactions of (Fos)aprepitant: review of literature and implications for clinical practice

\begin{tabular}{|c|c|c|}
\hline Drug class & Major CYP450 pathway & Comments \\
\hline \multirow[t]{10}{*}{ Antineoplastics } & Alkylating agents (CYP3A4 inhibition) & Slight increase in blood levels but no clinically significant impact \\
\hline & Cyclophosphamide & (cyclophosphamide); increases neurotoxicity with ifosphamide \\
\hline & Ifosphamide & \\
\hline & Topoisomerase inhibitor (CYP3A4 inhibition) & Theoretical increase in blood levels that requires close clinical monitoring \\
\hline & Etoposide & \\
\hline & Microtubule inhibitor (CYP3A4 inhibition) & Theoretical increase in blood levels that requires close clinical monitoring \\
\hline & Docetaxel/paclitaxel & \\
\hline & Tyrosine kinase inhibitor (CYP3A4 inhibition) & Theoretical increase in blood levels; increased levels noted with Erlotinib that can \\
\hline & Crizotinib & potentiate antitumor response \\
\hline & Erlotinib & \\
\hline \multirow[t]{5}{*}{ Opioids } & Opioids (CYP3A4 inhibition) & Monitor for respiratory depression and sedation \\
\hline & Oxycodone & \\
\hline & Fentanyl & \\
\hline & Hydrocodone & \\
\hline & Methadone & \\
\hline \multirow[t]{2}{*}{ Anticoagulants } & Warfarin (CYP2C9 induction) & Decreases INR that requires close monitoring and increased dosing \\
\hline & Apixiban/rivaroxaban (CYP3A4 inhibition) & Potential to increase bleeding that requires close monitoring \\
\hline
\end{tabular}

Notes: Adapted from Dushenkoy A, Kalabalik J, Carbone A, Jungsuwadee P. J Oncol Pharm Pract. Drug interactions with aprepitant or fosaprepitant: review of literature and implications for clinical practice. Epub February 25, 2016. Copyright @ 2016 by SAGE Publications. Reprinted by permission of SAGE Publications, Ltd.22 Abbreviation: INR, international normalized ratio.

derivative of aprepitant. The prodrug, fosaprepitant, is converted into the active aprepitant to exert its antiemetic properties. ${ }^{20}$

It is converted into the active drug, aprepitant, in hepatic and extrahepatic tissues (kidney, lungs, and ileum). Aprepitant is able to cross the blood-brain barrier and block the NK-1 receptor that is widely distributed in the central nervous system. Fosaprepitant has a half-life of approximately 2.3 minutes, with plasma levels below the level of detection in 30 minutes. In the plasma, more than $95 \%$ of the drug is protein bound. The volume of distribution of both aprepitant and fosaprepitant is $70 \mathrm{~L}$. Given the high volume of distribution, the drug stays in the body for a longer period of time, hence its efficacy for delayed CINV. ${ }^{21}$

Aprepitant is metabolized mainly by the CYP3A4, with minor metabolism via the CYP1A2 and CYP2C19. It is a moderate inhibitor of CYP3A4 and inducer of CYP2C9. In contrast, fosaprepitant is a weak inhibitor when administered as a single $150 \mathrm{mg}$ intravenous infusion. This becomes important for patients who take drugs that are likewise metabolized through this process because coadministration will need dose adjustments (Table 3). ${ }^{21,22}$

\section{Fosaprepitant - the missing link in antiemesis for cancer patients}

Aprepitant is one of the first NK-1 receptor antagonists approved for the prevention and management of nausea and vomiting brought about by moderately and highly emetogenic chemotherapy. It is conventionally administered orally for 3 days (125 mg on Day 1 and $80 \mathrm{mg}$ for Days 2 and 3).
It is generally combined with a serotonin antagonist (5-HT3) and dexamethasone. To improve compliance, the prodrug, fosaprepitant, was formulated. This is given as a single dose on Day 1 of chemotherapy as a $150 \mathrm{mg}$ intravenous infusion. That single dose is able to block $90 \%$ of NK-1 receptors. ${ }^{21,23}$

A study by Celio et $\mathrm{a}^{21}$ compared fosaprepitant and aprepitant in the management of acute and delayed CINV among patients treated with high-dose cisplatin. The results showed that fosaprepitant was noninferior to aprepitant. Both agents are highly efficacious for delayed CINV (nausea and vomiting after 24 hours of chemotherapy). ${ }^{21} \mathrm{~A}$ randomized, double-blind trial involving 2,322 patients receiving a cisplatin dose of $>70 \mathrm{mg} /$ $\mathrm{m}^{2}$ compared aprepitant (with ondansetron and dexamethasone) and fosaprepitant (with ondansetron and dexamethasone). The majority of these patients had lung and gastrointestinal malignancy. The results showed that a single dose of fosaprepitant was noninferior to a 3-day course of aprepitant. ${ }^{23}$

A 5-day course of aprepitant was compared with a single dose of fosaprepitant in patients receiving highly emetogenic chemotherapy (cisplatin dose $>60 \mathrm{mg} / \mathrm{m}^{2}$ ). There was no significant difference in the efficacy of the incidence of nausea and vomiting 7 days after chemotherapy between the two groups. ${ }^{24}$

Fosaprepitant has been compared to serotonin antagonist (5-HT3) - dexamethasone combination, the most common regimen used to treat CINV. A Phase III randomized doubleblind study compared a fosaprepitant regimen in combination with granisetron and dexamethasone vs granisetron and dexamethasone only. The end point of the study was a complete response defined as total absence of nausea and vomiting 


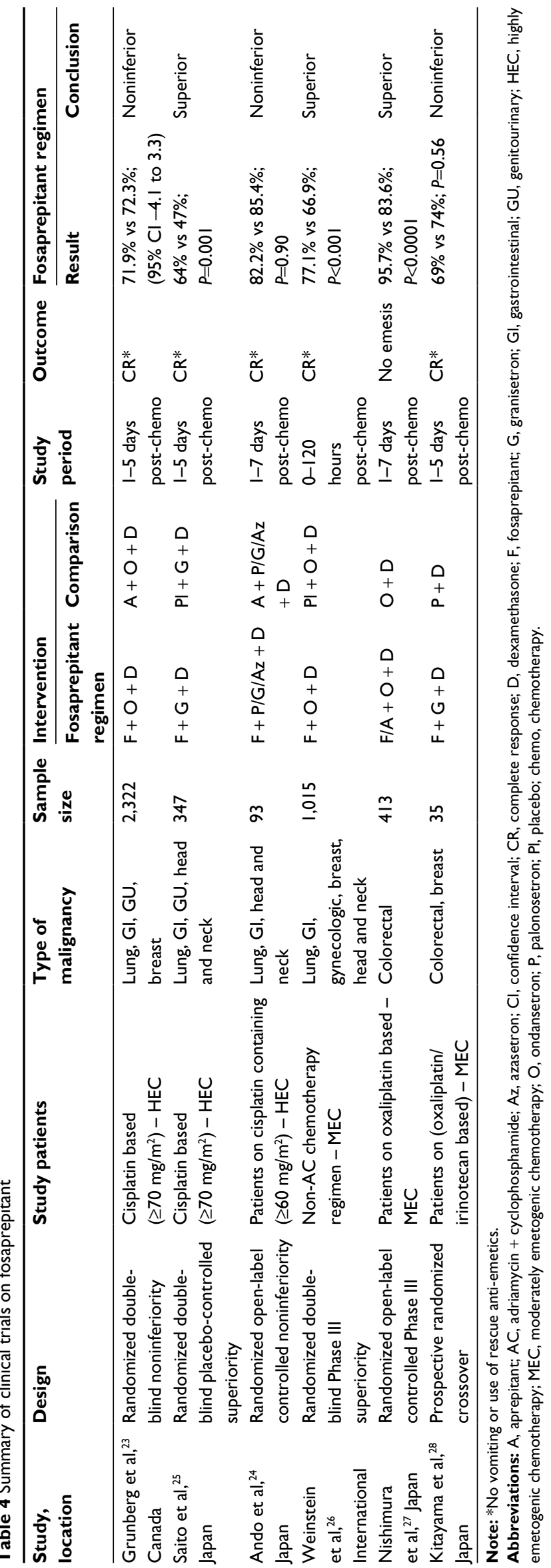

after a high dose of cisplatin. Overall, the fosaprepitant group had better complete response results (64\% vs $47 \%$ ). Fosaprepitant is effective in preventing both acute and delayed CINV, with a complete response of $94 \%$ and $65 \%$, respectively. ${ }^{25}$

Weinstein et $\mathrm{al}^{26}$ studied the use of a single-dose fosaprepitant vs ondansetron with dexamethasone for the prevention of CINV. There was no significant difference in the complete response in the acute phase (93.2\% vs $91 \%)$. However, in the delayed phase, fosaprepitant achieved higher complete response rates $(78.9 \%$ vs $68.5 \% ; P<0.001) .{ }^{26}$

A study involving the use of aprepitant or fosaprepitant combined with a 5-HT3 antagonist and dexamethasone in colorectal cancer patients receiving oxaliplatin-based chemotherapy showed that the aprepitant/fosaprepitant group achieved better antiemetic outcomes in the overall response rate and prevention of delayed CINV. ${ }^{27}$

Kitayama et $\mathrm{a}^{28}$ did a prospective randomized crossover study to evaluate the efficacy of palonosetron with dexamethasone vs fosaprepitant with granisetron and dexamethasone in the prevention of CINV among patients receiving moderately emetogenic chemotherapy and found no significant difference between the two groups.

Taking into account all these data, fosaprepitant is effective in the management of CINV, particularly for patients receiving moderately and highly emetogenic chemotherapy. An important benefit is the ability of this medication to control delayed CINV that can develop in the days after chemotherapy administration (Table 4). ${ }^{5}$

\section{Venous toxicity}

Fosaprepitant, like its oral counterpart aprepitant, is associated with side effects. These usually include anorexia, constipation, nausea, vomiting, diarrhea, hiccups, and asthenia. ${ }^{23,25}$ In a study evaluating a single dose of fosaprepitant for the prevention of CINV that included 1,143 patients receiving the drug, the most commonly noted side effects included constipation (10.6\%), asthenia (8.6\%), diarrhea (7.8\%), and vomiting (6.6\%). ${ }^{23}$ These adverse events were not significantly different from that of aprepitant. The study of Saito et $\mathrm{al}^{25}$ that compared a fosaprepitant regimen to that of granisetron revealed that the most common adverse event of fosaprepitant was leukopenia, which accounted for $59.2 \%$ (103 out of 174$)$ followed by anorexia $(51.7 \%)$ and nausea (43.7\%). Infusion site reaction is the major limiting adverse reaction during fosaprepitant administration. One study showed that $23.6 \%$ of patients receiving fosaprepitant developed an infusion site reaction. ${ }^{25}$ These reactions include pain, erythema, swelling, extravasation, and phlebitis. ${ }^{29}$ 
Table 5 Clinical practice guidelines in the management of chemotherapy-induced nausea and vomiting

\begin{tabular}{|c|c|c|c|}
\hline & High emetic risk & Moderate emetic risk & Low emetic risk \\
\hline $\mathrm{ASCO}^{\mathrm{a}}$ & $\begin{array}{l}\text { NK-I antagonist (aprepitant/fosaprepitant) + 5-HT3 } \\
\text { antagonist (granisetron/ondansetron/palonosetron/ } \\
\text { dolasetron/tropisetron/ramosetron) + dexamethasone }\end{array}$ & Palonosetron + dexamethasone & Dexamethasone \\
\hline $\mathrm{NCCN}^{\circledR, \mathrm{b}}$ & $\begin{array}{l}\text { NK-I antagonist (aprepitant/fosaprepitant/rolapitant) + } \\
5-\mathrm{HT} 3 \text { antagonist (dolasetron/ondansetron/granisetron/ } \\
\text { palonosetron) + dexamethasone } \\
\text { or } \\
\text { Netupitant + palonosetron + dexamethasone } \\
\text { or } \\
\text { Olanzapine + palonosetron + dexamethasone }\end{array}$ & $\begin{array}{l}\text { 5-HT3 antagonist (dolasetron/ondansetron/ } \\
\text { granisetron/palonosetron) + dexamethasone } \\
\text { with or without } \\
\text { NK-I antagonist (aprepitant/fosaprepitant/rolapitant) } \\
\text { or } \\
\text { netupitant + palonosetron + dexamethasone } \\
\text { or } \\
\text { olanzapine + palonosetron + dexamethasone }\end{array}$ & $\begin{array}{l}\text { Dexamethasone } \\
\text { or } \\
\text { prochlorperazine } \\
\text { or } \\
\text { 5-HT3 antagonist } \\
\text { (dolasetron/ } \\
\text { granisetron/ } \\
\text { ondansetron) }\end{array}$ \\
\hline $\begin{array}{l}\text { ESMO/ } \\
\text { MASCC }^{c}\end{array}$ & $\begin{array}{l}\text { NK-I antagonist (aprepitant/fosaprepitant) }+5-\mathrm{HT} 3 \\
\text { antagonist + dexamethasone }\end{array}$ & $\begin{array}{l}\text { AC regimen } \\
\mathrm{NK}-\mathrm{I} \text { antagonist (aprepitant/ fosaprepitant) + 5-HT3 } \\
\text { antagonist + dexamethasone } \\
\text { Non- } \mathrm{AC} \text { regimen } \\
\text { palonosetron + dexamethasone }\end{array}$ & $\begin{array}{l}\text { Dexamethasone } \\
\text { or } \\
5-\mathrm{HT} 3 \text { antagonist } \\
\text { or } \\
\text { Dopamine } \\
\text { antagonist }\end{array}$ \\
\hline
\end{tabular}

Notes: ${ }^{a}$ Data from Basch et al. ${ }^{6}$ 'Referenced from the NCCN Clinical Practice Guidelines in Oncology (NCCN Guidelines ${ }^{\circledR}$ ) for NCCN Guidelines for Antiemesis V.2.20।6. (c) National Comprehensive Cancer Network, Inc 2016. All rights reserved. Accessed March 3I, 2016. To view the most recent and complete version of the guideline, go online to www.nccn.org. NATIONAL COMPREHENSIVE CANCER NETWORK ${ }^{\circledast}$, NCCN ${ }^{\circledR}$, NCCN GUIDELINES ${ }^{\circledR}$, and all other NCCN Content are trademarks owned by the National Comprehensive Cancer Network, Inc. ${ }^{35}$ cAdapted from Roila F, Herrstedt J, Aapro M, et al. Guideline update for MASCC and ESMO in the prevention of chemotherapy- and radiotherapy-induced nausea and vomiting: results of the Perugia consensus conference. Annals of Oncology. 2010;2I(Suppl 5):v232-v243. By permission of Oxford University Press on behalf of the European Society for Medical Oncology. This image/content is not covered by the terms of the Creative Commons license of this publication. For permission to reuse, please contact the rights holder. Copyright $\odot$ 2010, Oxford University Press. ${ }^{36}$

Abbreviations: ASCO, American Society of Clinical Oncology; NCCN, National Comprehensive Cancer Network ${ }^{\circledast}$; ESMO, European Society of Medical Oncology; MASCC, Multinational Association of Supportive Care in Cancer; NK-I, neurokinin-I; 5-HT3, 5-hydroxytriptamine/serotonin; AC, anthracycline/cyclophosphamide.

In several studies, infusion site reactions have been associated with infusion of anthracycline-based chemotherapy. In a study by Sato et al, ${ }^{30}$ fosaprepitant coadministered with an anthracycline-based regimen was associated with a higher incidence $(67 \%)$ of infusion site reaction compared to regimens without anthracycline (16\%). A comparison of fosaprepitant infusion with anthracycline vs a cisplatin-based regimen showed that the former resulted in significantly higher infusion site reaction with an odds ratio of $12.95 .{ }^{31}$ In a study comparing fosaprepitant versus aprepitant when administered with the combined doxorubicin and cyclophosphamide, fosaprepitant resulted in higher infusion site reaction, $34.7 \%$ vs $2.3 \%{ }^{32}$ The mechanism of fosaprepitant-induced venous toxicity with an anthracycline-based regimen is poorly understood. A possible hypothesis is that both anthracycline chemotherapy and fosaprepitant cause impaired endothelial function, thus leading to venous toxicity. ${ }^{33}$ Thus, fosaprepitant should be avoided in patients receiving anthracycline, if possible. Otherwise, it should be administered with intravenous fluids in a proximal peripheral venous site as it has been associated with decreased chances of infusion site reaction. ${ }^{34}$ There have been no studies looking into fosaprepitant administration through a central venous access.

\section{Management of CINV}

There is variation among the different clinical practice guidelines in the management of CINV. Different medical oncology societies have published their own approach in treating CINV. These guidelines are summarized in Table 5.

\section{Conclusion}

CINV is a major dose-limiting side effect of cancer treatment. Fosaprepitant has been approved for the prevention and treatment of CINV caused by moderately and highly emetogenic chemotherapy. It was found to be more efficacious compared to serotonin antagonist - dexamethasone drug combination and is noninferior to aprepitant in the management of CINV. With single dosing, it offers better compliance. Infusion site reaction is a major side effect, especially when administered with an anthracycline-based regimen. Infusing in a more proximal peripheral site and with intravenous fluids appears to decrease the chances of venous toxicity.

\section{Disclosure}

The authors report no conflicts of interest in this work.

\section{References}

1. CDC.gov [homepage on the internet]. NCHS Data Brief: Leading Causes of Death 2013 (Number 64): United States. Centers of Disease Control and Prevention; 2013. Available from: http://cdc.gov/. Accessed January 5, 2016.

2. Micha JP, Rettenmaier MA, Brown JV 3rd, et al. A randomized controlled pilot study comparing the impact of aprepitant and fosaprepitant on chemotherapy induced nausea and vomiting in patients treated for gynecologic cancer. Int J Gynecol Cancer. 2016;26(2):389-393. 
3. Moradian S, Howell D. Prevention and management of chemotherapyinduced nausea and vomiting. Int J Palliat Nurs. 2015;21(5):216.

4. Ayers M, Olowe O. A systematic review: non pharmacologic interventions for chemotherapy induced nausea and vomiting. Honors Research Projects, Paper 110. 2015.

5. Schwartzberg LS, Rugo HS, Aapro MS. New and emerging therapeutic options for the management of chemotherapy-induced nausea and vomiting. Clin Adv Hematol Oncol. 2015;13(3 Suppl 3):3-13, 1.

6. Basch E, Prestrud AA, Hesketh PJ, et al; American Society of Clinical Oncology. Antiemetics: American Society of Clinical Oncology clinical practice guideline update. J Clin Oncol. 2011;29(31):4189-4198. Erratum in: J Clin Oncol. 2014;32(19):2117.

7. Janelsins MC, Tejani MA, Kamen C, Peoples AR, Mustian KM, Morrow GR. Current pharmacotherapy for chemotherapy-induced nausea and vomiting in cancer patients. Expert Opin Pharmacother. 2013;14(6):757-766.

8. Kamen C, Tejani MA, Chandwani K, et al. Anticipatory nausea and vomiting due to chemotherapy. Eur J Pharmacol. 2014;722:172-179.

9. Blackshaw LA, Brookes SJ, Grundy D, Schemann M. Sensory transmission in the gastrointestinal tract. Neurogastroenterol Motil. 2007; 19(1 Suppl):1-19.

10. Berthoud HR, Blackshaw LA, Brookes SJ, Grundy D. Neuroanatomy of extrinsic afferents supplying the gastrointestinal tract. Neurogastroenterol Motil. 2004;16(Suppl 1):28-33.

11. Grundy D. What activates visceral afferents? Gut. 2004;53(Suppl 2):ii5-ii8.

12. Grundy D. 5-HT system in the gut: roles in the regulation of visceral sensitivity and motor functions. Eur Rev Med Pharmacol Sci. 2008;12(Suppl 1):63-67.

13. Andrews PLR, Rudd JA. The role of tachykinins and the tachykinin K receptor in nausea and emesis. Handbook of Experimental Pharmacology, Vol 164. Berlin, Germany: Springer-Verlag; 2004:359-440.

14. Garcia-Recio S, Gascón P. Biological and pharmacological aspects of the NK1-receptor. Biomed Res Int. 2015;2015:495704.

15. Schnell FM. Chemotherapy-induced nausea and vomiting: the importance of acute antiemetic control. Oncologist. 2003;8(2):187-198.

16. Sekine I, Segawa Y, Kubota K, Saeki T. Risk factors of chemotherapyinduced nausea and vomiting: index for personalized antiemetic prophylaxis. Cancer Sci. 2013;104(6):711-717.

17. Osoba D, Zee B, Pater J, Warr D, Latreille J, Kaizer L. Determinants of postchemotherapy nausea and vomiting in patients with cancer. Quality of Life and Symptom Control Committees of the National Cancer Institute of Canada Clinical Trials Group. JClin Oncol. 1997;15(1):116-123.

18. Hesketh PJ. Chemotherapy-induced nausea and vomiting. $N$ Engl $J$ Med. 2008;358(23):2482-2494.

19. Cohen L, de Moor CA, Eisenberg P, Ming EE, Hu H. Chemotherapy-induced nausea and vomiting: incidence and impact on patient quality of life at community oncology settings. Support Care Cancer. 2007;15(5):497-503.

20. Colon-GonzalezF, Kraft WK. Pharmacokinetic evaluation of fosaprepitant dimeglumine. Expert Opin Drug Metab Toxicol. 2010;6(10):1277-1286.

21. Celio L, Ricchini F, De Braud F. Safety, efficacy, and patient acceptability of single-dose fosaprepitant regimen for the prevention of chemotherapy-induced nausea and vomiting. Patient Prefer Adherence. 2013;7: 391-400.

22. Dushenkoy A, Kalabalik J, Carbone A, Jungsuwadee P. Drug interactions with aprepitant or fosaprepitant: review of literature and implications for clinical practice. J Oncol Pharm Pract. Epub February 25, 2016.
23. Grunberg S, Chua D, Maru A, et al. Single-dose fosaprepitant for the prevention of chemotherapy-induced nausea and vomiting associated with cisplatin therapy: randomized, double-blind study protocol-EASE. J Clin Oncol. 2011;29(11):1495-1501.

24. Ando Y, Hayashi T, Ito K, et al. Comparison between 5-day aprepitant and single-dose fosaprepitant meglumine for preventing nausea and vomiting induced by cisplatin-based chemotherapy. Support Care Cancer. 2016;24(2):871-878.

25. Saito H, Yoshizawa H, Yoshimori K, et al. Efficacy and safety of singledose fosaprepitant in the prevention of chemotherapy-induced nausea and vomiting in patients receiving high-dose cisplatin: a multicentre, randomised, double-blind, placebo-controlled phase 3 trial. Ann Oncol. 2013;24(4):1067-1073.

26. Weinstein C, Jordan K, Green SA, et al. Single-dose fosaprepitant for the prevention of chemotherapy-induced nausea and vomiting associated with moderately emetogenic chemotherapy: results of a randomized, double-blind phase III trial. Ann Oncol. 2016;27(1):172-178.

27. Nishimura J, Satoh T, Fukunaga M, et al; Multi-center Clinical Study Group of Osaka, Colorectal Cancer Treatment Group (MCSGO). Combination antiemetic therapy with aprepitant/fosaprepitant in patients with colorectal cancer receiving oxaliplatin-based chemotherapy (SENRI trial): a multicentre, randomised, controlled phase 3 trial. Eur J Cancer. 2015;51(10):1274-1282.

28. Kitayama H, Tsuji Y, Sugiyama J, Doi A, Kondo T, Hirayama M. Efficacy of palonosetron and 1-day dexamethasone in moderately emetogenic chemotherapy compared with fosaprepitant, granisetron, and dexamethasone: a prospective randomized crossover study. Int $J$ Clin Oncol. 2015;20(6):1051-1056.

29. Hegerova LT, Leal AD, Grendahl DC, et al. An analysis of fosaprepitant-induced venous toxicity in patients receiving highly emetogenic chemotherapy. Support Care Cancer. 2015;23(1):55-59.

30. Sato Y, Kondo M, Inagaki A, et al. Highly frequent and enhanced injection site reaction induced by peripheral venous injection of fosaprepitant in anthracycline-treated patients. J Cancer. 2014;5(5):390-397.

31. Fujii T, Nishimura N, Urayama KY, et al. Differential impact of fosaprepitant on infusion site adverse events between cisplatin- and anthracyclinebased chemotherapy regimens. Anticancer Res. 2015;35(1):379-383.

32. Leal AD, Kadakia KC, Looker S, et al. Fosaprepitant-induced phlebitis: a focus on patients receiving doxorubicin/cyclophosphamide therapy. Support Care Cancer. 2014;22(5):1313-1317.

33. Chow AY, Chin C, Dahl G, Rosenthal DN. Anthracyclines cause endothelial injury in pediatric cancer patients: a pilot study. J Clin Oncol. 2006;24(6):925-928.

34. Lundberg JD, Crawford BS, Phillips G, Berger MJ, Wesolowski R. Incidence of infusion-site reactions associated with peripheral intravenous administration of fosaprepitant. Support Care Cancer. 2014;22(6):1461-1466.

35. National Comprehensive Cancer Network. NCCN Clinical Practice Guidelines in Oncology (NCCN Guidelines ${ }^{\mathbb{B}}$ ) for NCCN Guidelines for Antiemesis V.2.2016. Available from: https://www.nccn.org/professionals/physician_gls/f_guidelines.asp. Accessed March 31, 2016.

36. Roila F, Herrstedt J, Aapro M, et al; ESMO/MASCC Guidelines Working Group. Guideline update for MASCC and ESMO in the prevention of chemotherapy- and radiotherapy-induced nausea and vomiting: results of the Perugia consensus conference. Ann Oncol. 2010;21(Suppl 5): v232-v243.
Cancer Management and Research

\section{Publish your work in this journal}

Cancer Management and Research is an international, peer-reviewed open access journal focusing on cancer research and the optimal use of preventative and integrated treatment interventions to achieve improved outcomes, enhanced survival and quality of life for the cancer patient. The manuscript management system is completely online and includes

\section{Dovepress}

a very quick and fair peer-review system, which is all easy to use. Visit $\mathrm{http}: / / \mathrm{www}$.dovepress.com/testimonials.php to read real quotes from published authors. 